\title{
Soberanía política e imaginación cultural en tiempos
} coolture

\section{Political sovereignty and cultural imagination in times coolture}

- Omar Rincón

Universidad de los Andes, Colombia

\section{NOTAS BIOGRÁFICAS}

Omar Rincón es profesor asociado en el Centro de Estudios en Periodismo, CEPER de la Universidad de los Andres.

Contacto: orincon@uniandes.edu.co

\section{Resumen}

La sociedad del siglo XXI ha mutado de una cultura moderna ilustrada y crítica a una coolture entretenida y de flujo en la que la idea de mundo se concreta en navegar por las redes digitales y consumir felicidades. En la coolture, la cooperación internacional se privatiza y se hace entre individuos y empresas globalizadas basadas en el buena-ondismo y la caridad orientada por causas sociales, sin que intervenga el estado ni la política. Y para que funcione este nuevo sistema de cooperación, la comunicación y los medios digitales se convierten en el motor de desarrollo y creación de valor. Sin embargo, esta coolture no agota la imaginación social y surgen alternativas potentes desde el sur como son las culturas del buen vivir basadas en la ancestralidad andina o el movimiento de los vínculos del feminismo. En este ensayo, se parte de describir nuestro nuevo escenario de cooperación basado en fundaciones privadas, en una comunicación coolture y de redes difusas de identidad, para luego pasar a problematizar los conceptos de cooperación y desarrollo, y terminar proponiendo que la cooperación, la comunicación y el desarrollo requieren y exigen el diálogo intercultural como criterio fundamental para poder imaginar una sociedad distinta, más diversa y más solidaria.

\section{Abstract}

The society of the 21st century has changed from an enlightened and critical modern culture to an entertaining and flowing coolture in which the idea of the world is concretized in navigating the digital networks and consuming happiness. In this coolture, international cooperation is privatized and made between individuals and globalized companies, relying on new era and charity without state intervention or politics. And for this new cooperation system be possible, communication and digital media become the engine of development and creation of value. However, this coolness does not exhaust the social imagination and powerful alternatives emerge from the south, such as the cultures of good living based on Andean ancestry or the movement such as feminism. In this essay, we start by describing our new scenario of cooperation based on private foundations, in a communication coolture and diffuse identity networks, to then go on to problematize the concepts of cooperation and development, and end up proposing that cooperation, communication and development require and demand intercultural dialogue as a fundamental criterion to be able to imagine a different, more diverse and more solidary society. 


\section{Palabras clave}

Cultura, coolture, cooperación, comunicación, desarrollo, buen vivir, feminismo.

\section{Keywords}

Culture, coolture, cooperation, communication, development, good living, feminism.

\section{Sumario}

1. Introducción

2. El nuevo contexto mundial: la coolture

3. La cooperación al desarrollo

4. Hacia la soberanía comunicativa y cultural

5. El diálogo intercultural como cooperación, comunicación y desarrollo

6. Conclusión

\section{Contents}

1. Introduction

2. The new world context: the coolture

3. Cooperation for development

4. Towards communicative and cultural sovereignty

5. Intercultural dialogue such as cooperation, communication and development

6. Conclusion 


\section{INTRODUCCIÓN}

La cooperación en el área de comunicación y cultura en el siglo XX se hubiese podido esquematizar en tres modelos predominantes: El norteamericano que establece que lo político y lo cultural hacen parte de los instrumentos para defender los criterios de libre comercio, los derechos de autor y la libertad de expresión a través de USAID (Agencia de los Estados Unidos para el Desarrollo Internacional) y la NED (Fundación Nacional para la Democracia); el europeo que juega desde y solo desde lo cultural y mediático dejando de lado lo político y que reconoce que hay un diálogo entre diversas culturas donde lo importante es convivir y actuar conjuntamente en asuntos de arte y patrimonio y que tendría como referentes la AECID (Agencia Española de Cooperación Internacional para el Desarrollo); el alemán que establece que el Instituto Goethe, el DAAD (servicio Alemán de Intercambio Académico) y la Fundación Alexander-von-Humboldt desarrollan las estrategias principales para la cooperación científica y el diálogo intercultural; en lo comunicativo se hace vía la Deutsche Welle y las fundaciones políticas (Friedrich Ebert, Konrad Adenauer, Friedrich Naumann, Heinrich Böll, Rosa-Luxemburg); el gran ente a través del cual se organiza y dirigen las políticas de cooperación y desarrollo es el BMZ (Ministerio Federal de Cooperación Económica y Desarrollo). Cualquiera sea el modelo, la cooperación en comunicación y cultura responde a un discurso de encuentro donde se supone se fomenta "espacios comunes" de diálogo intercultural, cuando en la realidad es que "cada país sólo contemplaba a los otros como potenciales mercados de expansión comercial (Bustamante 2006, p. 8). Mientras la cooperación norteamericana enfatiza en la cultura del entretenimiento pop guiada por Hollywood, la europea se entronca en la cultura humanista moderna de las artes, el patrimonio y las capacidades culturales. Ambas tienen en común el pensar a la cooperación como expansión de mercados y desarrollo como progreso económico con barniz cultural.

Pero, en el siglo XXI estamos atravesando una mutación cultural (Baricco, 2008) que redefine la sociedad con la aparición de lo tecnológico digital (redes, internet, aplicaciones, plataformas, teléfonos inteligentes) con la consecuente hegemonía de las empresas de telecomunicaciones (Google, Facebook, Netflix....) como productoras de "la ilusión" de habitar un mismo mundo, al conectarse a las redes digita- les desde el "Smart phone". En este contexto cultural y tecnológico se da la mutación económica que ha llevado al triunfo de la ética capitalista y de mercado donde importa el individuo que consume (un sujeto "yopitalista" o capitalismo del yo), el ciudadano se convierte en dato que se compra y se vende (big data) y desaparece la densidad del Estado y las institucionalidades intermediadoras. Esto lleva a que la cooperación internacional sea hecha por fundaciones perteneciente a conglomerados privados (por ejemplo, la fundación Bill y Melinda Gates, Ford, Open Society, Avina), oenegés (organizaciones no gubernamentales como Green Peace, Médicos sin fronteras) y famosos pop (Bono, Shakira, Beyoncé) donde priman los intereses privados de las causas propias y el buena-ondismo sobre los problemas estructurales y urgentes de las sociedades. Entonces, la política desaparece y el Estado se dedica a crear las condiciones para la expansión del capitalismo en algo llamado industrias creativas (énfasis en lo mediático), economía naranja (énfasis en lo tecnológico), economía azul (énfasis en lo ambiental) que se logra a través de actitudes de innovación y creatividad, una sociedad de individuos al estilo Steve Jobs (Apple), Bill Gates (Microsoft), Jeff Bezos (Amazon) y Mark Zuckerberg (Facebook).

En este ecosistema económico-cultural del siglo XXI, pensar en cooperación cultural o comunicacional orientada a la promoción del diálogo entre culturas, el reconocimiento de las identidades y territorios diversos parece una herejía del atraso. La idea de que la comunicación significa desde y en lo cultural y, por tanto, reconoce la existencia de otras epistemologías, saberes y prácticas como las femeninas, las indígenas y originarias, las afro, las orientales, las populares, las campesinas, las precapitalistas, las poscapitalistas, las antisistemas, las LGTBI, las híbridas y bastardas es visto como un dispositivo "ideológico" que atrasa el desarrollo de la sociedad y el individuo; obviamente, estos "otros" sirven en cuanto individuos consumidores que permiten expandir mercados pero no interesan como sujetos y colectividades con saberes propios y modelos diversos de sociedad. En esta idea predominante de sociedad como mercado, ya no se necesita la cooperación cultural, ya que "todos somos mundo" e hijos de la cultura mainstream (Martel, 2011) que es made in USA y se convirtió en hegemónica gracias al celular "inteligente", la conexión a internet y a las plataformas. Solo hay un relato y una hegemonía (la tecnológica, el mercado y el individuo) que nos convierte en ciudadanos- 
mundo que "creamos valor" consumiendo experiencias de entretenimiento que nos hacen parte de esta gran comunidad higiénica mundializada de la coolture (Rincón, 2018).

En el siglo XX habíamos ganado en el discurso y en las políticas públicas que la comunicación tiene que ver y tiene sentido desde y en lo cultural (Martín Barbero, 1987; García Canclini, 1989). Y que, por eso, toda cooperación en comunicación es cultural y a la inversa, toda cooperación cultural es comunicacional. Pero este vínculo es el que está en peligro con la llegada de los mundos digitales que prometen habitar las coolture (Rincón, 2018) como aventura de consumo más allá de culturas de las artes, las identidades, el patrimonio y las soberanías locales.

En este ensayo, se parte de describir nuestro nuevo escenario de cooperación basado en fundaciones privadas, en una comunicación coolture y de redes difusas de identidad, para luego pasar a problematizar los conceptos de cooperación y desarrollo, y terminar proponiendo que la cooperación, la comunicación y el desarrollo requieren y exigen el diálogo inter-cultural como criterio fundamental para poder imaginar una sociedad distinta, más diversa y de juegos de diversos.

\section{EL NUEVO CONTEXTO MUNDIAL: LA COOLTURE}

El mundo era tranquilo en la modernidad mediática: uno se ilustraba por los libros y la prensa, se acompañaba del sonido popular de la radio y se emocionaba con la televisión, en los medios estaba el poder. Pero cayó un meteorito y creó una mutación cultural y política. Este meteorito comenzó con Arpanet (1969), siguió con la WWW (1990), se hizo cotidiana con el celular (1984), se volvió todo con el Iphone (2008). Llegaron los que van a decidir el mundo: Amazon (1994), Google (1998), Wikipedia (2001), Facebook (2004), Youtube (2005), Twitter (2006), Whats app (2009), Instagram (2010)... y vinieron mucho más aplicaciones, plataformas y con todo culminó en el reinado del big data, la nueva ideología (Rincón, 2016). Y la vida y el modo de habitar la realidad mutaron para siempre.

Manuel Castells (1997) señaló el nacimiento de una nueva sociedad marcada por una transformación en tres grandes niveles: en la economía a nivel de las relaciones de producción (globalización), en la política en las relaciones de poder (crisis Estado-Nación y partidos políticos, sociedad red) y en la cultura en las relaciones de experiencia (cibercultura), siendo en estas transformaciones las tecnologías de la información el eje común. Veinte años después comprobamos que las tecnologías digitales juegan un papel central en nuestras vidas ya que están en nuestra cotidianidad, llegan a todos los espacios sociales y de nuestras personas y nos imponen una "visión del mundo dada, vencedora, demoledora: la realidad es así (como plantea el neoliberalismo) y no podemos hacer nada por cambiarla" (Marí Sáez, 2001, p. 214).

Asistimos, citando a Ramonet (1997), al establecimiento de una sociedad informacional y global que se basa en cuatro atributos principales: permanente, planetario, inmediato e inmaterial. Un modelo de sociedad donde mandan el capitalismo financiero y los grandes grupos multimedia y donde la aflicción -ficciónde ser parte de una sociedad global intercomunicada y en este sentido, más igualitaria, nos mantiene adormecidos, navegando en una idea higienizada de la participación: estar en las redes y sin políticas como ideal de mundo.

Estamos en otro mundo. Lo digital es la palabra mágica para decir que se habita esta época. Lo digital se hace posible en "promiscuidad" de pantallas, plataformas, aplicaciones (apps) y redes. Y a eso que sale de ahí se le dice transmedia que nos indica que en lo narrativo cada dispositivo complementa, no copia, al otro; en lo interactivo invita a diversos modos del participar y crear; en el negocio cada creación es un modo de ganar dinero. Por el lado de los criterios de narración y expresión, los conceptos mágicos son los ejes de conexión (redcomunidad), participación (interacción y coproducción), narración (hipertexto-flujo-navegación) y programación (autonomía en la producción y el consumo). Según Carlos Scolari (2013), el profesor argentino experto en nuevos medios -lo transmedia-, hemos llegado a una nueva experiencia textual: nada muere, todo se transforma. A este mundo digital se le llama revolución, nuevo paradigma, ecología de medios y muchas más invenciones.

Y la democracia tuvo un sueño de renovación: todos podíamos ser ciudadanos digitales, ejercer nuestro poder desde la vida cotidiana. $Y$ esto porque el ejercicio de la ciudadanía encontró nuevos lugares de conectarse, expresarse y tejer poder. Los medios potentes del siglo XX y el periodismo “moderno", 
ahora sin centro, cayeron en una crisis de sentido y de relato, se convirtieron en jurásicos para estos tiempos de velocidad y flujo. Wikipedia es conocimiento colectivo, Facebook es periodismo de algoritmo, Twitter es comunicación visceral, Ebay es una tienda sin dueños.

Y así llegamos a la coolture es la cultura común del siglo XXI (Rincón, 2018). Esa del entretenimiento mundializado que establece como criterio de gusto a lo cool. Más que de pensadores o intelectuales está guiada por "influencers". Es esa que habita las tecnologías en red y plataforma y que se niegan a ser solo habitantes de la modernidad cultural y las patrias chicas. Esta es una cultura eminentemente comunicacional. $Y$ exige que los estados nacionales no interfieran en el libre flujo de productos, relatos y narrativas, que el mundo devenga una gestión algorítmica de Google, Facebook, Instagram, Apple, Amazon, Netflix, Uber, Airbnb que más que soberanía cultural busca flujos de tendencias, comunidades de fans, juegos de consumo. En este sentido, la cooperación en comunicación y cultura no existe, todos habitamos el mismo mundo y la misma experiencia, no se necesita de políticas culturales ni nada que limite el flujo indefinido de entretenimientos.

El habitar la coolture en la comunicación da cuenta de la convergencia digital como escenario, el predominio de las empresas globales de telecomunicaciones (Google, Facebook, Apple, Netflix) y la concentración e integración económica de las Industrias Culturales en grandes conglomerados transnacionales (Disney, Directv, Fox) que obligan a pensar en articular otras políticas de comunicación y cultura para ganar eficacia simbólica y económica y ojalá proveer espacios nacionales de soberanía cultural y espacios red regionales para crear condiciones de producción y consumo alternativas. $Y$ es que

las grandes corporaciones multinacionales tienden a ocupar simultáneamente los mercados masivos y los nichos locales ricos, controlando ambos por su poder sobre las redes de distribución (...) Se trata en suma de una "diversidad de mercado", con la imposición del todo mercancía y de la máxima rentabilidad sobre las especificidades y dinámicas culturales, con tendencia a asfixiar la ecología delicada en que radicaba la diversidad (creadores-productoresdistribuidores independientes, PYMES como cantera de innovación, espacios de no-mercado como resortes de equilibrio...). Y a eso se le puede llamar el triunfo de "una cultura clónica" (Bustamante, 2003), basada en la repetición incesante de éxitos comprobados, conservadores en la estética y descocados en ocasiones en la ética social, que tiende a marginar o ahogar toda creación innovadora, vanguardista, revulsiva, o localmente genuina en beneficio de la búsqueda incesante de mercados masivos. (Bustamante 2006, p. 4).

Todo parece ir en otra dirección ya que muchos países europeos y la mayoría de América latina han asumido el mandato de que "tecnologías para todos" y "acceso universal a internet" es todo lo requerido para que la sociedad se "modernice" y los ciudadanos asuman "su rol protagónico" en la democracia. Así, el discurso hegemónico que se asume es el de que las tecnologías "gradúan" de ciudadanos y que la industria de las telecomunicaciones podrán operarlo "sin ideología".

Y resulta que este devenir de la sociedad en una conexión digital "sin política" es una ideología, la del big data que actualiza el control y vigilancia sobre los ciudadanos, la que nos convierte a los ciudadanos en datos de compraventa (Rincón, 2016). Las tecnologías han hecho las revoluciones productivas del mundo, siempre. Esta ideología no es nueva, siempre han surgido utopías que afirman que estas tecnologías de la comunicación resuelven los problemas más acuciantes de la sociedad. Se argumentó, por ejemplo, que la televisión sería educación para todos, y resultó poco educativa, un tris informativo y mucho espectáculo (y es que la televisión es eso: relajación sin cabeza). Ahora el sueño son las Tics: la magia de la nueva democracia.

Todos los gobiernos de derecha e izquierda, si de eso existe algo hoy, alucinan en digital. Cada gobierno reparte obsesivamente tabletas, crean centros digitales, conectan usuarios, cierran brechas digitales y dicen que llegó la revolución: ahora si inclusión para todos. Todos compiten por tener aparatos, tabletas, celulares, conexiones. Y para eso se feria lo público (espectro, recursos y leyes) a favor de los privados porque se legisla en favor de los empresarios y en contra del Estado, lo público y lo ciudadano. Por ejemplo, el ministro TIC (Tecnologías de la Información y las Comunicaciones) de Colombia del 2010 a 2015, Diego Molano, afirmó que la conexión digital haría que "seamos un país moderno y próspero. De ahora en adelante la forma de arreglar los problemas de educación, justicia, agricultura, salud pública, pobreza y corrupción será con las TIC". Ojalá fuera todo tan determinista: una tableta y todo solucionado. Mucha hispteria, demasiado cinismo, poca verdad. 
El Estado y la soberanía nacional se inmolaron ante el discurso determinista de que las redes y las tecnologías nos harán libres y competitivos, y esto llevó a que habitemos una sociedad zombie (seguidores de pantallas y redes digitales) o sombie (adicta a los celulares inteligentes) que vive feliz en un ideal tecno-optimista a lo Trump y Bolsonaro, en el cual las redes llevaran a que los ciudadanos ejercerán directamente y sin intermediarios la democracia con "inteligencia" tecnológica. La realidad dice que no es automático el empoderamiento ciudadano; ya vemos como Trump y Bolsonaro con whats app y twitter dominan la política, los medios y los ciudadanos, y la democracia ha perdido su densidad.

\section{LA COOPERACIÓN AL DESARROLLO}

La cooperación ha estado dirigida hacia el desarrollo como progreso y modernización. Y se asume que el desarrollo significa llevar la innovación tecnológica o productiva o de sistema que ha servido en los países más avanzados para meterle velocidad al progreso de las instituciones políticas y sociales, los procesos productivos, el manejo de la economía y los recursos, la modernización de la educación, la salud y la justicia de sociedades que están en vía de desarrollarse en economía, democracia y humanismo. Aquí el problema es cómo se comprende "el desarrollo", ya que "implica un modelo económico en torno al cual gira todo, un modelo de crecimiento permanente que niega el carácter esencialmente cultural de los cambios sociales. El desarrollo implica la occidentalización forzosa del mundo, una voluntad de imponer un modelo cultural (...) el desarrollo en tanto en cuanto implica un continuo crecimiento económico y la homologación de este modelo en todas las sociedades (Chaparro, 2010, p. 6).

El desarrollo es el concepto movilizador de cooperación, pero a su vez es problemático respecto al modelo de sociedad en el que se juega. $\mathrm{Y}$ es que no hay un concepto único $\mathrm{e}$ indiscutible de lo que es el "desarrollo" y eso, a pesar de que casi ningún otro concepto político ha sido tan "unánimemente" consensuado, usado y promovido en la cooperación internacional y en las políticas nacionales.

Desarrollo, en general, equivale a la idea de la superación de la pobreza y la miseria a través de la generación de condiciones mínimas que satisfagan las necesidades básicas de las personas. El desarrollo es casi siempre un "cambio dirigido" de un objeto material, un proceso de producción, una estructura social. Pero también el consenso apunta a que el desarrollo "va más allá" de la garantía de esas condiciones básicas materiales.

El ideal de desarrollo sigue intrínsecamente ligado a la idea de superación del "atraso" y el alcance de un nivel de "evolución" equivalente al de países de Europa Occidental y Norteamérica, desconociendo muchas veces la mirada local, los contextos históricos y sociales en los países en los cuales se interviene para promover desarrollo. En términos simples, esta concepción de desarrollo sigue promoviendo la adaptación por parte de los países "en vía de desarrollo", de los modelos de democracia, de la adopción de tecnologías y sus usos, de la adaptación de los modos de relación social y cultural claramente enmarcados en la relación disfuncional norte-sur.

El Ilamado diálogo intercultural que -idealmente- debería ser la base de cualquier relación de cooperación, no pasa muchas veces de ser solo parte del discurso oficial, mediado claramente por las relaciones de poder que se empiezan a determinar a partir de la constelación país aportante/interventor - país receptor /intervenido, y de los intereses detrás de la intervención, determinada no solo a partir de las políticas de cooperación del país que "aporta", sino también de los intereses de los grupos de poder en el país intervenido. La palabra cooperación expresa un engaño porque no hay diálogo entre iguales sino imposición que hacen los países colonizadores o las fundaciones globalizadas del capital o las oenegés del "primer mundo", que son los que hacen "cooperación", los otros, los subdesarrollados, solo reciben esa "ayuda". La cooperación para el desarrollo no solo es dirigida sino, también, controlada.

La cooperación para el desarrollo tiene actores (los cooperantes), el objeto (modernizar) y los beneficiarios o población objetivo (los beneficiados) (Schicho, W. und Nöst, B, 2008, p. 46). La cooperación al desarrollo se dirige, prioritariamente, a las élites "aculturadas" de los países objeto de la cooperación y que por eso "la cooperación ha trabajado poco el diálogo social entre los ciudadanos de los diferentes países, ha trabajado mal el contacto entre organizaciones sociales de base y no ha terminado de reconocer la otredad" (Chaparro, 2010, p. 44). Nada más facilista para justificar las relaciones de inequidad y exclusión por parte de las élites políticas y económicas de los países en vía de desarrollo, que respaldarse en el discurso mis- 
mo del desarrollo y la cooperación como vía de superación de las inequidades, evadiendo la responsabilidad propia en la superación de las brechas económicas y las deficiencias de los propios sistemas políticos nacionales.

Hay una cooperación directa, Estado-Estado y hay una indirecta que se ejecuta a través de fondos concursables para ONG. En la primera priman los intereses del donante, hago cooperación si es útil a mi mercado. El patrimonio es turismo para los tours operadores occidentales, el cine es una inversión en un arte que se apoya en función del aporte de cada país, pero luego no se distribuye fuera y que no implanta cuotas de difusión. El mundo editorial no es bilateral, se apoya la lectura y la edición, pero las editoriales occidentales son las dominadoras y la producción propia no sale, no trasciende, no interesa el conocimiento del otro (Chaparro, 2015)

En el mismo sentido, Chaparro (2015) afirma que la cooperación vía ONG tiene errores de partida, el principal pensar que hay un mundo al que redimir, que es ignorante, no conoce el progreso y trata de incidir en reproducir comportamientos eurocéntricos. Pero en las ONG hay, al menos, algo más de bilateralidad en la cooperación y en la construcción de redes. En comunicación cultural se han hecho cosas en lo micro muy importantes en colaboración con redes ciudadanas y al margen de los estados. Esta siembra existe y es parte de la nueva consciencia.

Todo el discurso de la cooperación expresa, entonces, una contradicción implícita que se hace evidente en las relaciones de dependencia, condicionalidad e intervención con las que actúa; la cooperación en lo concreto es una imposición de modelos culturales que se concretan en lo económico entendido como desarrollo y mercado de consumo.

Pasando a nuestra contemporanidad descrita arriba donde triunfa la coolture y la cooperación se ha privatizado y se ha convertido en estrategia de expansión de los mercados, el individuo y el capitalismo, el desarrollo se concibe como los modos en que se usa al ciudadano en cuanto usuario, consumidor y "emprendedor" en los mundos digitales y de la cultura (visión del mercado); o es concebirlo como ciudadano y productor de contenidos (eje en la cultura); o es su posibilidad de ejercer su libertad de expresión (eje en los derechos); o es participar del progreso y la justicia social (eje de la política).

Lo que es claro es que hay que comenzar a desmontar esa idea de un desarrollo, una cooperación y una democracia basada en un único discurso hegemónico: el occidental, blanco y masculino. Es necesario reconocer el aporte de otras culturas al mundo que compartimos. Y es que bajo nuestro "modelo de desarrollo" nos asusta "el otro", el diferente, el diverso. Y es ahí donde la relación cultura-comunicación es clave producir una cooperación de diálogo, que fortalezca la construcción de imaginarios comunes y promueva la interculturalidad.

\section{HACIA LA SOBERANÍA COMUNICATIVA Y CULTURAL}

En esta línea de comunicación-cultura la cooperación ideal debería partir del reconocimiento de que las comunidades, los territorios y los sujetos en todas las culturas tienen voces, saberes, prácticas y experiencias propias con las cuáles entrar en el diálogo intercultural. Chaparro (2010, p. 43) propone que "el concepto de cooperación cultural es más amplio que el concepto de cooperación al desarrollo", ya que "la cooperación en cultura es más equitativa y horizontal y se fundamenta en el reconocimiento de la otredad. El eje cultura-comunicación viene a superar el concepto tradicional de cooperación, con el inconveniente de que sus resultados no se pueden medir a corto plazo".

Y para ese diálogo intercultural en perspectiva progresista el piso común debería ser los derechos humanos (Chaparro 2010, p. 45). Y en este momento histórico, además, trabajar con los jóvenes, las mujeres, los migrantes, las comunidades LGTBI, los movimientos ambientales, ya que son estos grupos los que están activando unas nuevas formas de hacer la política y unos nuevos imaginarios de sistema mundo. Obviamente sin olvidar los asuntos clásicos de la cooperación como son el patrimonio, la educación y la formación civil.

Se propone entonces una cooperación cultural como criterio para guiar a la comunicación y al desarrollo, una cooperación que

más que promover la integración de países, debe buscar la integración de ciudadanos, trabajando los denominadores comunes definidos en las Declaraciones Universales de los Derechos Humanos, Pueblos Indígenas y Medio Ambiente. Es éste el capítulo más deficitario de nuestra cooperación y el que exige mayores esfuerzos. Cultura y comunicación deben servir para promover el diálogo de los ciudadanos de ambas orillas potenciando su encuentro e intercambiando conocimientos, inquietudes, ideas, ambiciones y folklores; en suma, tejiendo complicidades que 
superen recelos históricos más allá de querellas políticas, a veces de exclusiva propiedad de los gobiernos (Chaparro, 2010, p. 54).

El imperativo político es otro: una cooperación en comunicación y cultura más allá del criterio del mercado y lo tecnológico desde la soberanía cultural del ciudadano y los territorios. Significa volver a resignificar lo que llamó la atención Jesús Martín Barbero (2005) de que los Estados nacionales y la cooperación cultural deberían asumir al sector de medios y tecnologías como un sector de los servicios públicos estratégico socialmente más allá de su instrumentalidad.

Entre los buenos ejemplos de cooperación internacional española en cultura-comunicación en Latinoamérica se puede citar al Programa Ibermedia de ayuda a la producción cinematográfica; el apoyo a procesos legislativos de democratización de medios, a medios comunitarios para facilitar el diálogo y el empoderamiento de la sociedad civil; el intercambio científico universitario; la ayuda al patrimonio (Chaparro, 2010, p. 16).

El programa Ibermedia demuestra la viabilidad de la construcción progresiva de un espacio común audiovisual. Sin embargo, "en este programa primó la producción frente a la distribución efectiva o la promoción; y olvidó generalmente la concepción de un audiovisual integral, especialmente de la imprescindible pata televisiva, a falta de la cual resulta imposible completar la financiación y amortización de los productos, o cambiar la imagen de los públicos iberoamericanos sobre su propia identidad audiovisual" (Bustamante, 2006, p. 8).

Uno de los estudiosos que más sabe de cooperación en comunicación y cultura, Enrique Bustamante afirma que "en sentido positivo, se juega además el fin de unas políticas de Estado que se han dedicado no pocas veces a cultivar el pasado (el patrimonio) o las artes más elitistas, dejando abandonado el futuro (las industrias culturales, incluyendo los medios de comunicación) al mercado. 0 que, incluso en esos casos, han centrado su protección sobre la producción de bienes culturales, olvidándose de crear condiciones propicias para la creatividaden el monte de la cadena de producción- y de fomentar la distribución y la promoción (en el valle) indispensables" (Bustamante, 2006, p. 2). El asunto ahora es articular sin perder diversidad, participar del espacio global sin diluir la soberanía cultural.

La cooperación en comunicación y cultura y las políticas nacionales al respecto deben pro- pender la diversidad cultural y el diálogo intercultural. Las líneas de actuación estatal, de la cooperación internacional y de la sociedad civil que propone Bustamante son: (i) Respecto a las redes de comunicación potenciar la expansión de las redes digitales menos costosas y más proclives al servicio universal, en el sentido de asequible pero también asequible a todos los ciudadanos. El criterio debe ser pasar del acceso individual y de pago del modelo estadunidense a uno gratuito y colectivo. (ii) Promover una política anti-concentración sobre todo la concentración cruzada entre medios, redes y soportes digitales. (iii) Una política sistemática de apoyo a la creación, la edición y la difusión de la cultura que tenga como centro a la sociedad civil; una política que articule el mercado con el Estado y la sociedad civil. (iv) Restaurar el objetivo central de las políticas culturales y de comunicación que es el ciudadano. (v) Un sistema público de comunicación y cultura expandido cuyo criterio no sea el mercado (Bustamante, 2006, p. 7).

En la misma línea, expertos en internet y defensores de la libertad de expresión como Observacom [Observatorio Latinoamericano de Regulación, Medios y Convergencia] (2018) proponen llegar a una "smart regulation", una propuesta de regulación democrática y mínima que reglamente a los gigantes tecnológicos para garantizar una Internet libre y abierta, así como el pleno ejercicio de la libertad de expresión e información y la soberanía audiovisual. Se sugiere una regulación NO de los contenidos de redes, plataformas y servicios audiovisuales, sino una regulación de los dueños de esas plataformas y los canales con el objetivo de proteger a los ciudadanos ante su creciente poder. Una regulación mínima que siga los instrumentos internacionales sobre derechos humanos y que deberá tomar en cuenta las asimetrías existentes creadas por el mercado. Algún atisbo de optimismo nos trae el informe de la Comisión del Parlamento del Reino Unido cuando afirma, por ejemplo, que Facebook y las plataformas son unos "gangsters digitales", ya que estas empresas "no pueden esconderse detrás de la afirmación de ser simplemente una "plataforma" y mantener que ellos no tienen ninguna responsabilidad en la regulación del contenido de sus sitios".

Una última propuesta está en un grupo académico mundial que investigó y diseñó una agenda mínima de lo que sería progreso social en términos de comunicación (Couldry y Rodríguez, 2018). Ellos afirmaban con criterio que "actualmente más personas pueden dar a conocer sus ideas y estar conectadas a través de los 
medios, lo cual constituye un recurso importante para crear nuevos movimientos en favor de la justicia y el progreso social (Couldry y Rodríguez, 2018, p. 8). Pero, también, Ilaman la atención sobre como "la inequidad en la distribución de oportunidades de acceso y uso de los medios es en sí misma una dimensión de la justicia social (ya que) la expansión de las infraestructuras mediáticas y el acceso a los medios no han sido igualitarios" (Couldry y Rodríguez, 2018, p. 8). Este estudio mundial propone como acciones urgentes para que la comunicación sirva al progreso y la justicia social las siguientes:

Garantizar el acceso asequible, confiable, sostenible y efectivo a las infraestructuras de comunicación.

Que los temas de inclusión, asequibilidad y diversidad en los medios ocupen un lugar central, por encima del mercado y el lucro.

Posicionar los derechos de la comunicación que incluyen: el derecho a ser creador de contenido; el derecho a la libre expresión; el derecho al conocimiento y la información, y el derecho a la privacidad.

Que la sociedad civil participe en la gobernanza y la formulación de políticas sobre Internet e infraestructuras de medios.

El diseño de plataformas mediáticas receptivas al insumo de diversos individuos y comunidades -especialmente de grupos marginados, como las comunidades negras, las minorías de género, los grupos LGBTI, las comunidades discapacitadas y las comunidades del Sur Global.

Una regulación sobre medios e Internet que proteja a los usuarios contra la vigilancia estatal y/o corporativa y la extracción de datos para propósitos de control o mercadeo.

Promover marcos regulatorios de los medios y de Internet que prohíban cualquier tipo de censura o discriminación por discapacidad, género, orientación sexual o afiliación política, religiosa o étnica.

Fomentar la creación de contenidos propios.

El alfabetismo mediático e informacional.

La promoción del periodismo independiente como elemento esencial de la democracia $y$, para este fin, explorar modelos alternativos de financiaciones adicionales al comercial (formas innovadoras de alianza público-privadas, tarifas por licencia, etc.). Promover el acceso libre a software y al libre conocimiento como bienes comunes de la humanidad (Couldry y Rodríguez, 2018, pp. 99-100).
En la propuesta de Bustamante (2006) la cooperación y las políticas públicas de comunicación, cultura y desarrollo deben estar orientadas al ciudadano; en la propuesta de Observacom el criterio debe ser la libertad de expresión y la pluralidad y diversidad de opinión, y en el estudio de Couldry y Rodríguez (2018) el horizonte lo debe establecer los ODS (Objetivos de Desarrollo Sostenible) y el Índice de Progreso Social [IPS].

En este escenario la lucha comunicacional mundial es por la democratización de la comunicación, ya que en nuestro contexto geo-político "la cooperación se debe centrar en un mayor trabajo de democratización basado en la búsqueda del empoderamiento ciudadano. Ello facilitará la toma de decisiones, la construcción de sociedades más locales y autosuficientes y, por supuesto, el reconocimiento de la diversidad cultural (...) El fin de la cooperación debe ser la supresión de las barreras y las primeras deben ser las que más nos pueden llegar a separar, es decir, las de la incomunicación y la desconfianza cultural entre los pueblos" (Chaparro, 2010, p. 7).

\section{EL DIÁLOGO INTERCULTURAL COMO COOPERACIÓN, COMUNICACIÓN Y DESARROLLO}

Pero la comunicación no es solo medios y tecnologías, y el desarrollo en comunicación no es solo acceso y conexiones digitales, no es solo progreso y modernización, es más... es acerca de lo cultural, lo político, el modelo de sociedad. Por eso, la cooperación en comunicación y desarrollo debería tener como orientación el buen vivir (propuesta desde las culturas ancestrales), una economía del cuidado (propuesta desde el feminismo) y una sociedad de los derechos (propuesta de la modernidad). Un modelo que describe Arturo Escobar (2016) como "desde abajo, por la izquierda y con la tierra”.

Un listado de las tendencias más notables del pensamiento crítico latinoamericano tendría que incluir, entre otras, las críticas a la modernidad y a la teoría decolonial; los feminismos autónomos, decoloniales, y comunitarios; la diversa gama de debates ecológicos y de economías alternativas, incluyendo la ecología política, la economía social y solidaria (ESS), las economías comunales; las posiciones autonómicas; otras y nuevas espiritualidades; y las diferentes propuesta de transiciones civilizatorias, el posdesarrollo, el Buen Vivir, y 
el post-extractivismo (... reconocer que...) los conocimientos de los pueblos en movimiento, de las comunidades en resistencia y de muchos movimientos sociales están en la avanzada del pensamiento para las transiciones, y cobran una relevancia inusitada para la reconstitución de mundos ante las graves crisis ecológicas y sociales que enfrentamos, más aun que los conocimientos de expertos, las instituciones y la academia (...por lo cual hay que incluir en el espacio epistémico y social a los ) 'pensamiento autonómico' y 'pensamiento de la Tierra', (...) movimientos que enfatizan la reconstitución de lo comunal y territorial como el pilar de la autonomía (... y) pensamiento de la Tierra (...) no tanto al movimiento ambientalista y a la ecología sino a aquella dimensión que toda comunidad que habita un territorio sabe que es vital para su existencia: su conexión indisoluble con la Tierra y con todos los seres vivos. (Escobar, 2016).

Es en otro desarrollo donde haremos la diferencia, allí el mercado y lo tecnológico no son el valor principal, ni la meta; existen, son nuestro mar donde navegar, pero estarán al servicio del proyecto político de las comunidades.

En esta línea quiero enfatizar en el carácter dialógico intercultural que atraviesan a las tres categorías que estamos trabajando: Comunicación, Desarrollo y Cooperación. A las tres es prioritario partir y tener como centro el diálogo entre culturas, las tres deben buscar lo que Pablo Freire (1985) imaginaba en Pedagogía del oprimido: reconocer que todos tenemos cultura, saberes, experiencias y sentidos; que el diálogo entre iguales y basado en la escucha del otro, nos permite a todos tener voz y conciencia crítica de nuestro lugar en el mundo. Por eso la clave de lo intercultural es ese encuentro sabroso con el otro, ese llegar a jugar desde y en los sentidos diversos de los modos diferentes de habitar el mundo, eso que la economía del cuidado feminista nos propone, eso de la ética del buen vivir que practican las comunidades ancestrales. Y es que "si cooperación implica la complicidad entre dos o más agentes para alcanzar un fin, ésta debe tener un objetivo bidireccional que facilite los flujos y los intercambios" (Chaparro, 2010, p. 6).

Los lazos del eje comunicación-cultura deben contribuir a repensar nuevos imaginarios sociales, potenciar la democracia, diversificar las narrativas, proveer desde y en los medios y tecnologías nuevos modos de enunciación, encontrar en las culturas otras estéticas y formatos disidentes, juegos de sentido y humanismos diversos. La idea es la comunicación jugando desde y en la interculturalidad que parta de los territorios y las identidades locales para desde ahí construir un modo propio de habitar la sociedad. Ahí la cooperación debe ser y tiene que ser de diálogo intercultural donde no hay un único desarrollo ni una única cultura.

Lo urgente es diversificar el concepto de felicidad como promesa del capitalismo, una felicidad que solo se logra en el consumo, hay que ir hacia otros modos de ser felices. Y tal vez habría que pensar como dice el filósofo Byung-Chul (2019) que "necesitamos un tiempo propio que el sistema productivo no nos deja; requerimos de un tiempo de fiesta, que significa estar parados, sin nada productivo que hacer, pero que no debe confundirse con un tiempo de recuperación para seguir trabajando; el tiempo trabajado es tiempo perdido, no es tiempo para nosotros".

La idea es que la cooperación, la cultura, la comunicación diversifiquen, estallen y expandan el concepto o ideal de desarrollo y cooperación. El horizonte debe ser la democracia, el ciudadano, la vida en común. $Y$ ahí los movimientos sociales, las luchas LGTBI, las comunidades indígenas, los modos afros, las propuestas feministas abren posibilidades inéditas para nuestra sociedad.

Soñar no cuesta nada, pero la realidad del mundo se mueve por otros cauces: el capitalismo para todos en el consumo y las redes digitales, cooperación más de privados que de Estados, más de famosos pop que de sociedad civil. Antes de concluir quiero plantear tres modos de comprender la relación comunicación, cultura y desarrollo, una desde la coolture (la cultura de lo igual en la promesa de diversidad digital) que se ha convertido lo más común, otra desde las culturas ancestrales que plantea el modelo del buen vivir como alternativa todavía imposible de realizar, y una final desde el feminismo que nos aterriza en un modelo posible para intervenir el capitalismo financiero hacia la economía de los vínculos.

Desde la coolture, quiere poner toda la crónica que escribe el economista, exministro y académico Alejando Gaviria porque es ejemplar en cómo desde el mundo empresarial y los famosos del pop se concibe la cooperación y el desarrollo. Y dice así:

La foto fue publicada en la primera página por los principales diarios de la región hace algunas semanas. Mostraba al presidente del Banco Interamericano de Desarrollo (BID), Luis Alberto Moreno, rodeado por Juanes, Shakira, Alejandro Sanz, Ricky Martin y otros cantantes de moda.El encuentro tuvo lugar en Miami, durante la asam- 
blea anual del BID, una cita obligada para los banqueros de la región. Los artistas no acudieron, como en el pasado, a entretener a los financistas. Todo lo contrario. Fueron a hablar de desarrollo económico, a exponer sus opiniones sobre cómo acabar con la pobreza y la desigualdad social.

"Creo que sería muy importante que cada uno de nosotros se considere a sí mismo como un gobierno y se sienta capaz de hacer cosas por los demás", dijo uno de ellos con inocultable voluntarismo. El desarrollo económico, en este comienzo de siglo, parece ser asunto de la farándula. Los académicos quedaron atrás. Ya no salen en la foto.

"Yo soy un cantante con un buen oído para la melodía. Y las buenas ideas tienen mucho en común con las buenas melodías. Cierta claridad. Cierto aire inevitable y memorable" dice Bono, el decano de los rockeros del desarrollo. Hace 40 años, los rockeros cantaban las melodías de la contracultura. Actualmente, mantienen intacto el apetito por cambiar el mundo, pero sus tonadas son una muestra predecible de 'bienpensantismo'. Proponemos, dice Bono, "una ecuación que combine el capital humano y el financiero, los objetivos estratégicos del mundo desarrollado con la nueva planeación del mundo en desarrollo". La letra no es memorable. Pero, hay que reconocerlo, está de moda.

La alianza entre artistas y banqueros es previsible. Es un ejemplo más de lo que uno de los instigadores del Mayo del 68 francés, el marxista Guy Debord, llamó La sociedad del espectáculo. Pero más allá de la domesticación de la contracultura, el reclutamiento de los cantantes por parte de las entidades multilaterales refleja la quiebra intelectual de la economía del desarrollo. Los cantantes no desplazaron a los teóricos, llenaron el vacío dejado por algunas teorías desprestigiadas.

Como lo ha afirmado, entre otros, el economista William Easterly, las teorías del desarrollo que planteaban un camino expedito, o al menos cierto, hacia la prosperidad se han ido derrumbando una a uno bajo el peso de sus propios fracasos. Muchas de las grandes inversiones financiadas con capital internacional que iban a darles el gran empujón a los países en desarrollo acabaron convertidas en elefantes blancos. Las inversiones en educación, también financiadas con recursos externos, tampoco tuvieron los réditos esperados. Los créditos de ajuste estructural fueron inocuos en el mejor de los casos y contraproducentes en el peor. En fin, gran parte de las intervenciones de las multilaterales ha sido, cabe decirlo sin ambages, un fracaso.

El nuevo credo del desarrollo predica una mayor participación del sector privado en la solución de los problemas sociales. La rentabilidad y el altruismo, dicen, se encuentran en la base de la pirámide. Algunas de las iniciativas planteadas son interesantes. Pero ya nadie cree en milagros. El desarrollo financiado desde afuera, importado en la forma de créditos, ayuda o carreta, es un producto desprestigiado. Por ello, tal vez, toca reclutar a los artistas. Las buenas intenciones siempre han sido eficaces a la hora de vender ilusiones. Así, la foto del Presidente del BID, sonriente, rodeado por los artistas más consagrados de la región, representa, tal vez, un punto de inflexión en la historia de las multilaterales, una aceptación implícita de que su papel es más simbólico que real, de que su labor consiste en mantener, como dijo Albert Hirschman, un sesgo por la esperanza después del derrumbe de las utopías del desarrollo.

Juanes y su combo, repletos de buenas intenciones, pueden haber entonado, sin saberlo, la canción de despedida de las multilaterales. Un aporte que va más allá de la música. En cualquier momento del año, Shakira toma un avión y llega a Colombia para conocer cómo avanzan las obras de un colegio en Ciudad Bolívar que auspicia su Fundación Pies Descalzos. Al mismo tiempo, Juanes asiste a un encuentro de su Fundación Mi Sangre en un municipio de Antioquia para escuchar de viva voz la recuperación física y mental de una víctima de las minas antipersona. Por su parte, Carlos Vives y su organización La Tierra del Olvido realizan una brigada de salud en una localidad del Magdalena. Estos son sólo tres ejemplos de la contribución que realizan a la sociedad colombiana tres de los artistas nacionales más reconocidos. Su actitud hace parte de una tendencia mundial en la que los músicos intentan realizar aportes que van más allá de los escenarios artísticos. Bono, Ricky Martín, Miguel Bosé y Alejandro Sanz, entre otros, buscan demostrarlo día a día (Gaviria, 2008).

Este es el buena-ondismo que se impone como ideología del mundo desde y en el mercado y que va triunfando ya que propone una cooperación internacional entre entes privados, sin Estados, cada uno en su "interés", en su "altruismo", en "su caridad", y que se olvida de la intermediación de la cultura, la política, el Estado. Pero como dice el texto, este modelo de cooperación significa el fracaso de los grupos multilaterales y eso de préstamos internacionales para el desarrollo, el fracaso de una idea de desarrollo en función de derechos, la evidencia que el capitalismo no es altruista y que la economía no resuelve el bienestar humano.

Frente a esta nueva ideología sin política de la privatización de la sociedad global (dicen ellos que ni son ideológicos ni son políticos, pero es una nueva ideología), existe el descubrimiento más brillante de nuestros mundos académicos: El buen vivir indígena que el preámbulo de la Constitución de Bolivia narra orgánicamente así: 
En tiempos inmemoriales se erigieron montañas, se desplazaron ríos, se formaron lagos. Nuestra amazonia, nuestro chaco, nuestro altiplano y nuestros llanos y valles se cubrieron de verdores y flores.

Poblamos esta sagrada Madre Tierra con rostros diferentes, y comprendimos desde entonces la pluralidad vigente de todas las cosas y nuestra diversidad como seres y culturas. Así conformamos nuestros pueblos, y jamás comprendimos el racismo hasta que lo sufrimos desde los funestos tiempos de la colonia.

El pueblo boliviano, de composición plural, desde la profundidad de la historia, inspirado en las luchas del pasado, en la sublevación indígena anticolonial, en la independencia, en las luchas populares de liberación, en las marchas indígenas, sociales y sindicales, en las guerras del agua y de octubre, en las luchas por la tierra y territorio, y con la memoria de nuestros mártires, construimos un nuevo Estado.

Un Estado basado en el respeto e igualdad entre todos, con principios de soberanía, dignidad, complementariedad, solidaridad, armonía y equidad en la distribución y redistribución del producto social, donde predomine la búsqueda del vivir bien; con respeto a la pluralidad económica, social, jurídica, política y cultural de los habitantes de esta tierra; en convivencia colectiva con acceso al agua, trabajo, educación, salud y vivienda para todos.

Dejamos en el pasado el Estado colonial, republicano y neoliberal. Asumimos el reto histórico de construir colectivamente el Estado Unitario Social de Derecho Plurinacional Comunitario, que integra y articula los propósitos de avanzar hacia una Bolivia democrática, productiva, portadora e inspiradora de la paz, comprometida con el desarrollo integral y con la libre determinación de los pueblos.

Nosotros, mujeres y hombres, a través de la Asamblea Constituyente y con el poder originario del pueblo, manifestamos nuestro compromiso con la unidad e integridad del país. Cumpliendo el mandato de nuestros pueblos, con la fortaleza de nuestra Pachamama y gracias a Dios, refundamos Bolivia. Honor y gloria a los mártires de la gesta constituyente y liberadora, que han hecho posible esta nueva historia. (Constitución Política del Estado, 2009).

Hermoso. Utópico. Imaginativo. Ancestral. Cultural. Todo un manifiesto intercultural y de dignidad en el territorio. Un nuevo mundo, tal vez imposible en esta sociedad donde triunfó el capitalismo, que propone como horizonte de criterios éticos distintos: más que capital, el vivir bien; más que el mercado y la competencia, poner la soberanía, la dignidad, la complementariedad, la solidaridad en el centro; de establecer unos mínimos básicos como son los derechos al agua, trabajo, educación, salud y vivienda para todos.

Este relato nos mueve a una cooperación y comunicación alternativa a la sociedad capitalista, la del buen vivir que imagina "una sociedad de la vida buena en plenitud, con armonía personal, social, con la naturaleza y con el cosmos" (Contreras, 2016, p. 24). Una comunicación como "un proceso de construcción, de/construcción y re/construcción de sentidos sociales, culturales, políticos y espirituales de convivencia intercultural y comunitaria con reciprocidad, complementariedades y solidaridad... en el ejercicio del Derecho a la Comunicación... que es participativa y dialogal" (Contreras, 2016, pp. 75-76). Esta comunicación para el Buen Vivir sigue tres requisitos: “1) ser expresiones de una epistemología del sur; 2) sostener un paradigma comunicacional de diálogo; 3) insertarse en el campo político y del "desarrollo" (Contreras 2016, p. 21) para democratizar la palabra y practicar la interculturalidad.

Por ahora, va ganando por goleada la visión nueva era coolture, esa del buenaodismo, y una sociedad en clave del buen vivir es más una utopía que un posible real porque implicaría hacer una sociedad distinta con un modelo político y económico que pusiera al ser humano, a las culturas, a la madre tierra en el centro de su eficiencia y limitar la voracidad financiera del capitalismo, y este desmonte del modelo capitalista no ha sido posible en ninguna sociedad. Por ahora va ganando el capitalismo para todos, o sea el ideal de todos podemos consumir y participara de la fiesta del mercado.

Una tercera propuesta de cooperación, desarrollo y comunicación que hackea al capitalismo sin destruirlo y permite imaginar otros modos de estar y ser sociedad se inscribe en el movimiento feminista que está demostrando que se puede activar desde los cuerpos, desde las autonomías colectivas, desde la economía de los vínculos, desde la cooperación por el cuidado:

una politicidad en clave femenina es -no por esencia sino por experiencia histórica acumulada-, en primer lugar una política del arraigo espacial y comunitario; no es utópica sino tópica; pragmática y orientada por las contingencias y no principista en su moralidad; próxima y no burocrática; investida en el proceso más que en el producto; y sobre todo solucionadora de problemas y preservadora de la vida en lo cotidiano (...) un proyecto histórico de los vínculos (que) insta a la reciprocidad, que produce comunidad. (Segato, 2018, pp. 15-16). 
Una cooperación y comunicación inscrita en lo comunal, en lo pragmático y coyuntural, de cercanía y colaborativa, que soluciona asuntos cotidianos y promueve la economía de los vínculos. Las mujeres ya nos están mostrado que otro desarrollo, otra cooperación, otra comunicación es posible con su presencia en las calles, en la política; comunicativamente, el movimiento feminista es tendencia de sentidos, es digital, es activista, es irreverente y juega a politizar desde lo contracultural. Tal vez, ahí encontremos las experiencias y prácticas para salir del modelo de desarrollo en el que el mercado nos quiere aprisionar. Ser contracultural siempre es posible y las mujeres nos indican los modos, las formas, los discursos y los mundos para hacerlo.

\section{CONCLUSIÓN}

Si la comunicación cultura debe ser parte de la cooperación será para construir nuevas estrategias de diálogo intercultural y redes de colectivos sociales en la búsqueda de soluciones propias y la promoción de otras enunciaciones públicas. Así mismo, debe proveer de nuevos relatos, otros imaginarios, diversificar las experiencias de referencia, politizar desde y en los cuerpos. Si la comunicación-cultura quiere entender nuevas rutas deberá asumir la existencia de otras narrativas, estéticas, epistemologías híbridas y bastardas que nacen en las identidades de los otros, en especial, las mujeres, los indígenas, los afros y el movimiento trans. La comunicación cultura debe construir nuevas políticas de acceso a los medios que propicien encuentros y generen unas narrativas diversas y disidentes que enfaticen en la fiesta de lo humano y lo cultural y no en la eficiencia y productividad del capital.

\section{REFERENCIAS BIBLIOGRÁFICAS}

- Baricco, A. (2008). Los Bárbaros. Ensayos sobre la mutación. Barcelona: Anagrama.

- Bustamante, E. (2006). Diversidad en la era digital: La cooperación iberoamericana cultural y comunicativa. Pensar Iberoamericano, 9. Recuperado de:

https://www.oei.es/historico/pensariberoamerica /ric09a03.htm.

- Castells, M. (1997). La era de la información. Economía, sociedad y cultura, Volumen 1: La sociedad red. Madrid: Alianza.
- Chaparro, M. (2015). Claves para repensar los medios y el mundo que habitamos. La distopia del desarrollo. Bogotá: Desde abajo.

- Chaparro, M. (2010). Cooperación en culturacomunicación en el Mediterráneo. España, Francia e Italia con Marruecos, Túnez y Argelia. Creando espejos. Barcelona: Fundación Alternativas

- Contreras, A. (2016). La palabra que camina. Comunicación popular para el Vivir Bien/Buen Vivir. Quito: Ciespal.

- Constitución Política del Estado. Gaceta Oficial de Bolivia. 9 de febrero de 2009. Recuperada de: http://www.oas.org/DIL/ESP/Constitucion_Bolivi a.pdf.

- Couldry, N. y Rodríguez, C. (2018). Desigualdad y luchas comunicativas en tiempos globales (Informe global por una comunicación comprometida con el progreso social). Bogotá: FES Comunicación.

- Escobar, A. (17 de enero de 2016). Desde abajo, por la izquierda y con la Tierra. El País. Recuperado de:

https://elpais.com/elpais/2016/01/17/contrapun tos/1453037037_145303.html.

- Freire, P. (1985). Pedagogía del oprimido. Montevideo: Tierra Nueva.

- García Canclini, N. (Ed.). (1989). Culturas Híbridas. México: Grijalbo.

- Gaviria, A. (11 de mayo de 2008). Farándula y desarrollo. El Espectador. Recuperado de: http://www.elespectador.com/impreso/negocios/ articuloimpreso-farandula-y-desarrollo.

- Geli, C. (7de febrero,2018). "Ahora uno se explota a símismo y creeque estárealizándose”. El País. Recuperado de: https://elpais.com/cultura/2018/02/07/actualida d/1517989873_086219.html.

- Martel, F. (2011). Cultura Mainstream. Madrid: Taurus.

- Marí Sáez, V.M. (2001). De las banderas al viento a las redes multiformes. Tecnologías de la información, movimientos sociales y cambio social, contextos, modelos organizativos y estrategias comunicativas". En Quirós Fernández, F. y Sierra Caballero, F. Comunicación, globalización y democracia. Crítica de la economía política de la comunicación y la cultura (pp. 211-230). Sevilla: Comunicación Social Ediciones Publicaciones.

- Martín Barbero, J. (1987). De los medios a las mediaciones. Barcelona: Gustavo Gili.

- Martín Barbero, J. (2005). Políticas de interculturalidad. Observatorio $n^{\circ}$ 2. Dossier Diversidad Cultural.

- Facebook no es transparente sobre sus decisiones de remoción de contenidos y suspensión de cuentas, según estudio de Electronic Frontiers 
Foundation (8 de junio de 2018). Observacom. Recuperado de:

http://www.observacom.org/facebook-no-estransparente-sobre-sus-decisiones-de-remocionde-contenidos-y-suspension-de-cuentas-segunestudio-de-electronic-frontiers-foundation/.

- Ramonet, I. (1997). Un mundo sin rumbo. Crisis del fin de siglo. Madrid: Debate.

- Rincón, 0 (2018). La coolture. Revista Anfibia. Recuperado de: http://revistaanfibia.com/ensayo/la-coolture/.

- Rincón, O. (2016). Los datos: la cancha donde se juega la democracia. Chasqui. Revista Latinoamericana de Comunicación, 131, 21-35.

- Schicho, W.und Nöst, B. (2008). Entwicklungsdiskurs und Praxis der EZA: Konzepte, Akteure und Widersprüche. En De Abreau Fialho Gomes, B.; Maral-Hanak,I.; Schicho, W. (Hg.) Entwicklungszusammenarbeit. Akteure, Handlungsmuster und Interessen. Wien: Mandelbaum.

- Scolari, C. (2013). Narrativa Transmedia: cuando todos los medios cuentan. Barcelona: Deusto S.A ediciones.

- Segato, R. (2018). Contra-pedagogías de la crueldad. Buenos Aires: Prometeo. 